\title{
A Torilis japonica extract exerts anti-proliferative activities on the U87MG human glioblastoma cell line
}

\author{
HYE-WON JUNG and SUNG-HO GHIL
}

Department of Life Science, Kyonggi University, Suwon 443-760, Korea

Received July 30, 2010; Accepted August 26, 2010

DOI: $10.3892 / \mathrm{mmr} .2010 .376$

\begin{abstract}
Torilis japonica is a wild biennial herb and has been used as a traditional medicine for the treatment of inflammation, skin disease and impotence. Here, we studied the effects of a T. japonica extract on the proliferation of the U87MG human glioblastoma cell line. The extract inhibited cell proliferation in a dose- and time-dependent manner, as determined using the MTT assay. We next investigated the molecular mechanisms underlying its anti-proliferation properties by examining cell cycle progression and cell death. T.japonica extract induced S-phase cell cycle arrest and inhibited the expression of cell cycle-regulatory proteins, including cyclin A, cyclin-dependent protein kinase 2 and E2F1. The extract also induced apoptotic cell death as evaluated by nuclear morphology and flow cytometry using Annexin-V/ PI dual staining. Furthermore, Western blot analysis showed that apoptotic cell death was mediated by both mitochondriaindependent and caspase-dependent pathways. Together, our findings indicate that the $T$. japonica extract contains bioactive compounds with anti-cancer effects. These materials may be useful in the chemotherapy of human glioblastoma.
\end{abstract}

\section{Introduction}

Glioblastomas are the most common primary brain tumors and arise from the transformation of astrocytes or glial precursors (1). The most common and aggressive form of glioblastoma is glioblastoma multiforme (GBM). Patients with GBM usually have a short survival time, with 2-year survival rates of only $6 \%$ (2). Despite many therapeutic developments, including surgery, radiation therapy and chemotherapy, glioblastoma patients continue to have a dismal prognosis (3).

Several lines of evidence indicate that bioactive ingredients in natural plant extracts may be effective against glioblastomas. A Hemsleya amabilis extract inhibited tumor cell growth and colony formation, and induced apoptotic cell

Correspondence to: Dr Sung Ho Ghil, Department of Life Science, Kyonggi University, Suwon 443-760, Korea

E-mail: shghil@kgu.ac.kr

Key words: anti-proliferation, apoptosis, cell cycle, glioblastoma, Torilis japonica death in astrocytomas (4). Elemene isolated from Rhizoma zedoariae exhibited anti-proliferative and apoptotic effects on glioblastoma cells of the C6 and SHG-44 lines (5). A lipidsoluble extract of Angelica sinensis inhibited proliferation of the GBM 8401 glioblastoma cell line and had an in vivo anti-cancer effect (6). Triptolide, derived from Tripterygium wilfordii, inhibited cell growth and both the p53-independent and mitochondria-dependent apoptotic cell death pathways in the glioblastoma lines U251MG and U87MG. This extract also reduced Ras/Erk levels and lowered the activity of the Ras/Akt signaling pathway $(7,8)$.

Torilis japonica is a biennial herb widely found in Eastern Asia. Its fruits have been used as a traditional medicine for the treatment of inflammation, skin disease and impotence (9). The major component of T. japonica is torilin, a sesquiterpene compound. Recently, it has been found that torilin has various pharmacological activities, including analgesic, antiinflammatory, anti-angiogenic and hepatoprotective effects. Furthermore, torilin inhibits testosterone $5 \alpha$-reductase (10-13). However, the anti-cancer effects, if any, of T. japonica extract on glioblastoma cells has not been studied.

In the present study, we found that $T$. japonica extract significantly reduced U87MG cell proliferation in a dose- and time-dependent manner. We also investigated the molecular mechanisms underlying these anti-proliferative activities.

\section{Materials and methods}

Preparation of T. japonica extract. Dried fruits of T. japonica were purchased from the Kyungdong oriental medicine market in Seoul, Korea. Dried fruit (100 g) was extracted with $99.8 \%$ methanol (1 1 ) for $72 \mathrm{~h}$ at room temperature, and the extract was concentrated by rotary evaporation. The extract was next partitioned using ethyl acetate and water (1:1). The ethyl acetate phase was further partitioned employing hexane and 90\% methanol (1:1). The 90\% methanol phase was evaporated to dryness and the residue dissolved in dimethyl sulfoxide (DMSO; Sigma-Aldrich, St. Louis, MO, USA).

Cell culture. The human glioblastoma cell line U87MG was cultured in Dulbecco's modified Eagle's medium supplemented with $10 \%$ fetal bovine serum, $100 \mathrm{U} / \mathrm{ml}$ penicillin and $100 \mu \mathrm{g} / \mathrm{ml}$ streptomycin (all from Hyclone, South Logan, UT, USA) and was incubated at $37^{\circ} \mathrm{C}$ in a humidified incubator under $5 \% \mathrm{CO}_{2}$. 
Cell proliferation assay. U87MG cells $\left(3 \times 10^{3}\right)$ were plated in the wells of 96-well plates. After a 24-h incubation, the cells were treated with various concentrations of $T$. japonica extract $(0-100 \mu \mathrm{g} / \mathrm{ml})$ for the indicated times. After incubation, $10 \mu \mathrm{l}$ MTT solution ( $5 \mathrm{mg} / \mathrm{ml}$ ) (Sigma) was added to each well and the cells were further incubated for $4 \mathrm{~h}$ at $37^{\circ} \mathrm{C}$. Next, $100 \mu \mathrm{l}$ of isopropyl alcohol dissolved in $5 \% 1 \mathrm{~N} \mathrm{HCl}$ was added to solubilize formazan crystals. Absorbance was measured using a SpectraMax Plus ${ }^{384}$ microplate reader (Molecular Devices, Sunnyvale, CA, USA). The DMSO concentration never exceeded $0.5 \%$.

Cell cycle analysis. U87MG cells were plated into tissue culture dishes $100 \mathrm{~mm}$ in diameter at a density of $2 \times 10^{5}$ cells/dish and treated with the indicated concentrations of T. japonica extract for $48 \mathrm{~h}$. Cells were harvested by trypsinization, washed with ice-cold PBS and fixed in 70\% ethanol for $20 \mathrm{~min}$. Fixed cells were stained with a propidium iodide (PI) solution (PBS containing $50 \mu \mathrm{g} / \mathrm{ml} \mathrm{PI,} 10 \mu \mathrm{g} / \mathrm{ml}$ RNase A and $3.8 \mathrm{mM}$ sodium citrate) at $4^{\circ} \mathrm{C}$ for $20 \mathrm{~min}$. Flow cytometry was performed using a FACSCanto (BD Biosciences, San Diego, CA, USA). Data from 10,000 cells per sample were collected and analyzed.

Nuclear morphology study. U87MG cells were plated on coverslips at a density of $5 \times 10^{3}$ cells/coverslip and treated with $T$. japonica extract $(10 \mu \mathrm{g} / \mathrm{ml})$. After a 48 -h incubation, cells were fixed in $4 \%$ paraformaldehyde for $10 \mathrm{~min}$ and nuclei were stained with $10 \mu \mathrm{g} / \mathrm{ml}$ Hoechst 33258 (Sigma) for $20 \mathrm{~min}$. Nuclear morphology was observed by fluorescence microscopy (BX-50; Olympus, Tokyo, Japan).

Flow cytometry with Annexin-V/PI dual staining. U87MG cells $\left(2 \times 10^{5}\right.$ cells/dish) were plated on culture dishes $100 \mathrm{~mm}$ in diameter and treated with the indicated concentrations of T. japonica extract for $60 \mathrm{~h}$. Next, the cells were fixed in $70 \%$ ethanol for $20 \mathrm{~min}$. Annexin-V/PI dual staining was performed using the Annexin-V-FITC Apoptosis Detection kit I (BD Biosciences), according to the manufacturer's protocol. Samples were analyzed by FACSCanto flow cytometry. Data from 10,000 cells per sample were collected and analyzed.

Western blot analysis. U87MG cells were plated into tissue culture dishes $100 \mathrm{~mm}$ in diameter at a density of $2 \times 10^{5}$ cells/ dish and treated with the indicated concentrations of T.japonica extract for $48 \mathrm{~h}$. Cells were next lysed in PBTX buffer (PBS containing $5 \mathrm{mM} \mathrm{MgCl} 2,1 \mathrm{mM}$ EDTA and $0.1 \%$ Triton X-100) also containing protease inhibitors $(5 \mu \mathrm{g} / \mathrm{ml}$ aprotin, $10 \mu \mathrm{g} / \mathrm{ml}$ leupeptin, $2 \mu \mathrm{g} / \mathrm{ml}$ pepstatin A and $2 \mathrm{mM}$ phenylmethylsulfonyl fluoride) for $1 \mathrm{~h}$ with constant rocking at $4^{\circ} \mathrm{C}$. Total cell lysate was collected after centrifugation at $12,000 \mathrm{rpm}$ at $4^{\circ} \mathrm{C}$ for $10 \mathrm{~min}$. Cell lysates were run on 8-12\% SDS-PAGE gels and transferred to PVDF membranes (Westran S; Whatman, Florham Park, NJ, USA). Membranes were blocked for 1-2 $\mathrm{h}$ at room temperature with 5\% non-fat dry milk and incubated with antibodies against cyclin A, cyclin-dependent protein kinase 2 (cdk2), E2F1, Bax, Bcl-2, caspase-3, caspase-7, caspase-8, poly (ADP-ribose) polymerase (PARP)-1/2 (all at a 1:500 dilution) (all antibodies were from Santa Cruz Biotechnology, Santa Cruz, CA, USA), or $\alpha$-tubulin (1:2,500 dilution; Upstate

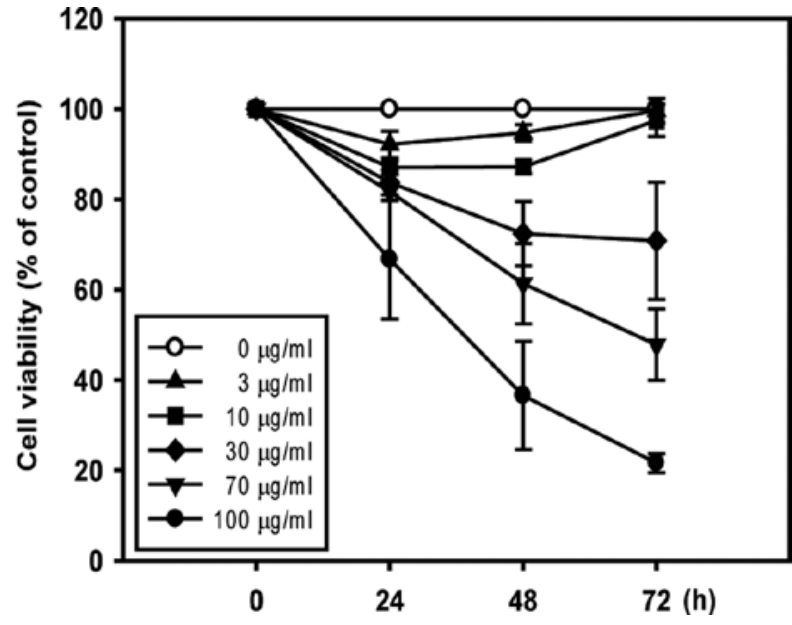

Figure 1. Effect of T. japonica extract on the proliferation of U87MG cells Cells were treated with the T. japonica extract at various concentrations for different times, and cell death was evaluated using the MTT assay. The data are the average \pm SE of values from three independent experiments.

Biotechnology, Temecula, CA, USA). Membranes were next incubated with the appropriate secondary antibodies, either a goat anti-mouse IgG horseradish peroxidase (HRP) conjugate (1:5,000 dilution) or a goat anti-rabbit IgG HRP conjugate (1:25,000 dilution; both from Zymed, Carlsbad, CA, USA), for $1 \mathrm{~h}$ at $25^{\circ} \mathrm{C}$, and bands were visualized with the aid of an enhanced chemiluminescence detection kit (West-Zol ${ }^{\circledR}$; Intron Biotechnology, Sungnam, Korea).

\section{Results}

Effect of T. japonica extract on the proliferation of the human glioblastoma cell line U87MG. To investigate the effect of T. japonica extract on U87MG proliferation, cells were treated with $0-100 \mu \mathrm{g} / \mathrm{ml}$ of $T$. japonica extract for the indicated times and cell proliferation rates were determined using the MTT assay. Fig. 1 shows that the extract inhibited cell proliferation in a dose- and time-dependent manner. The median effective doses $\left(\mathrm{EC}_{50}\right.$ values) of the extract were 175.3, 78.6 and 59.6 $\mu \mathrm{g} /$ $\mathrm{ml}$ at 24,48 and $72 \mathrm{~h}$, respectively.

Effect of T. japonica extract on cell cycle progression. Next, the basis of the anti-proliferative activity of the extract was investigated. U87MG cells treated with the indicated concentrations of extract for $48 \mathrm{~h}$ were stained with PI and subjected to flow cytometry analysis. Application of extract increased the proportion of cells in the S-phase and reduced the proportions in the G1- and G2/M-phase compared to control cells (Fig. 2A). To determine the mechanisms of extract-induced cell cycle arrest, Western blot analysis was performed using antibodies against $\mathrm{S}$-phase cell cycle regulatory proteins, including cyclin A, cdk2 and E2F1. The expression levels of these proteins were decreased in a dose-dependent manner upon treatment with extract (Fig. 2B). These results indicate that $T$. japonica extract arrests cell cycle progression in the S-phase in U87MG cells.

Effect of T. japonica extract on apoptotic cell death. To investigate the effect of the extract on the apoptotic cell death 
A
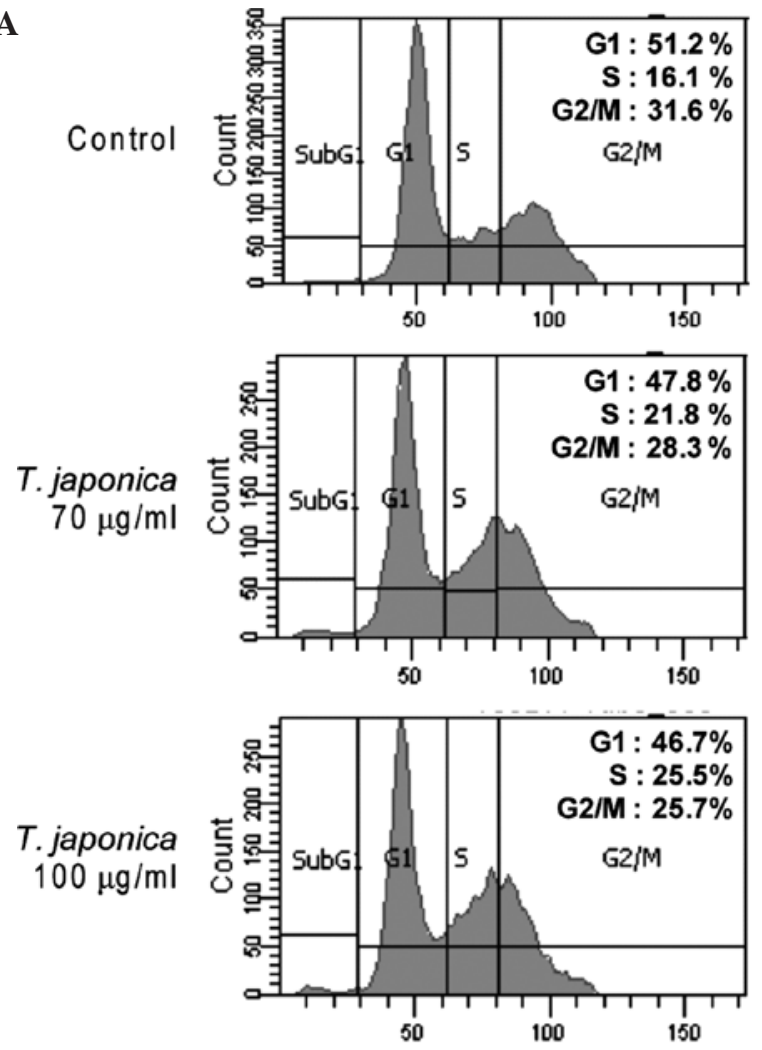

B

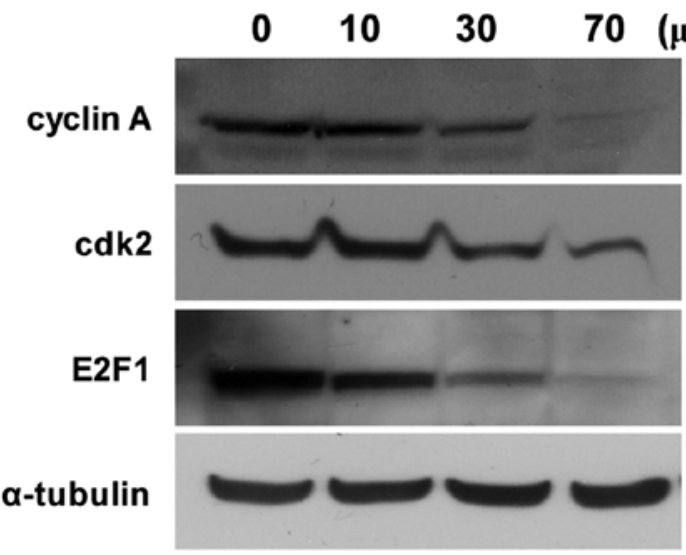

Figure 2. Effect of T. japonica extract on cell cycle progression in U87MG cells. Cells were incubated with the indicated concentrations of $T$. japonica extract for 48 h. (A) Cells were stained by PI and next analyzed by flow cytometry. (B) Cells were subjected to Western blot analysis using antibodies against S-phase cell cycle-regulating proteins, including cyclin A, cdk2 and E2F1. $\alpha$-tubulin was used as an internal control.

of U87MG cells, cells were treated with the extract prior to staining with Hoechst 33258. As shown in Fig. 3A, nuclear condensation was evident at an extract dose of $10 \mu \mathrm{g} / \mathrm{ml}$ after $48 \mathrm{~h}$ of treatment, suggesting that apoptotic cell death was occurring. To confirm the apoptosis-promoting potential of the extract, cells were treated with extract at the indicated concentrations for $60 \mathrm{~h}$, and then Annexin-V/PI dual staining was performed followed by flow cytometry. The dot plot shows non-apoptotic liver cells in the lower left quadrant (AnnexinV-negative/PI-negative), apoptotic cells in the lower right quadrant (Annexin-V-positive/PI-negative) and late apoptotic or necrotic cells in the upper right quadrant (Annexin-V-positive/
PI-positive). The proportion of apoptotic cells was increased in a dose-dependent manner upon the addition of extract (Fig. 3B). To investigate the mechanism of extract-induced apoptosis, cells were treated with extract at the indicated concentrations for $48 \mathrm{~h}$, and then Western blotting was performed using antibodies against apoptosis-related proteins. It is known that a reduction in the expression ratio of the Bcl-2/Bax proteins indicates mitochondrial dysfunction (14). We found that the $\mathrm{Bcl}-2 / \mathrm{Bax}$ ratios in treated cells did not differ significantly from the control value (Fig. 3C), suggesting that the extract did not cause mitochondrial dysfunction in U87MG cells. Caspases are activated by a mitochondria-independent death receptor signaling pathway or by mitochondria-dependent cytochrome $c$ release (15). Of the various caspases, caspase- 8 relays the signal from a death receptor to other caspases, including caspase- 3 and -7 . Treatment with extract activated caspase- $3,-7$ and -8 , suggesting that the extract induces apoptotic cell death through both death receptor-mediated and caspase-dependent signaling pathways (Fig. 3C). Additional evidence for caspase involvement was the cleavage of PARP, observed upon caspase activation. Treatment of U87MG cells with extract resulted in the formation of the characteristic PARP-derived $85 \mathrm{kDa}$ protein fragment in a dose-dependent manner (Fig. 3C).

\section{Discussion}

In the present study, we focused on the anti-proliferative activity of a T. japonica extract and the molecular mechanisms thereof, using the human glioblastoma cell line U87MG. Treatment with $T$. japonica extract significantly inhibited the proliferation of U87MG cells in a dose- and time-dependent manner. The application of extract induced S-phase cell cycle arrest by reducing the expression levels of cell cycle-regulating proteins. Additionally, the extract induced apoptosis via the mitochondria-independent and caspase-dependent signaling pathways. These results indicate that $T$. japonica extract potently inhibits U87MG cell proliferation by inducing both cell cycle arrest and apoptosis.

The cell cycle is regulated by complexes of cyclins and cdks (16). Cyclin A, a member of the cyclin family (a group of proteins involved in the control of cell cycle progression), binds to cdk2 and is required if a cell is to progress through the S-phase, during which time chromosomes are replicated by DNA polymerase (17). The cyclin A/cdk2 complex phosphorylates retinoblastoma protein, which in turn activates the E2F1 transcription factor involved in the expression of genes required for DNA synthesis and cell cycle progression $(18,19)$. As shown in Fig. 2, T. japonica extract significantly downregulated the expression of cyclin A, cdk 2 and E2F1 in a dose-dependent manner, suggesting a possible explanation for the observed S-phase cell cycle arrest.

Mitochondria-dependent apoptosis is accompanied by a change in the levels of the expression of Bcl-2 family members. Increased synthesis of pro-apoptotic proteins (including Bax and Bak) and reduced expression of anti-apoptotic proteins (including Bcl-2 and Bcl-xL) activate the release of cytochrome $c$ from mitochondria into the cytosol (20-22). As shown in Fig. 3C, T. japonica extract did not alter Bcl-2 or Bax expression levels, suggesting that the extract induces apoptosis via a mitochondria-independent mechanism. 
A
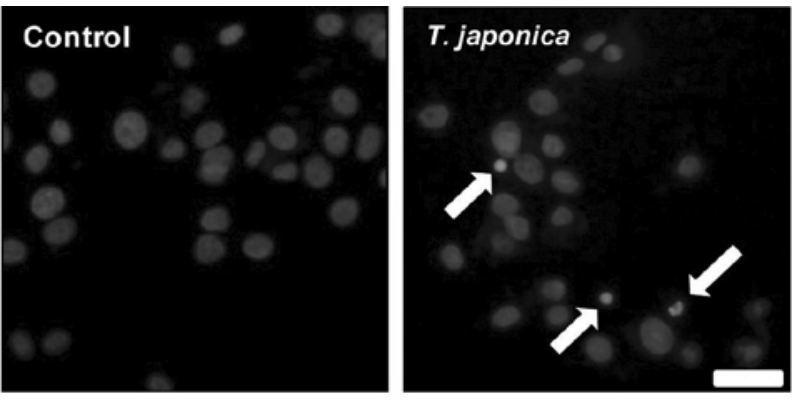

B

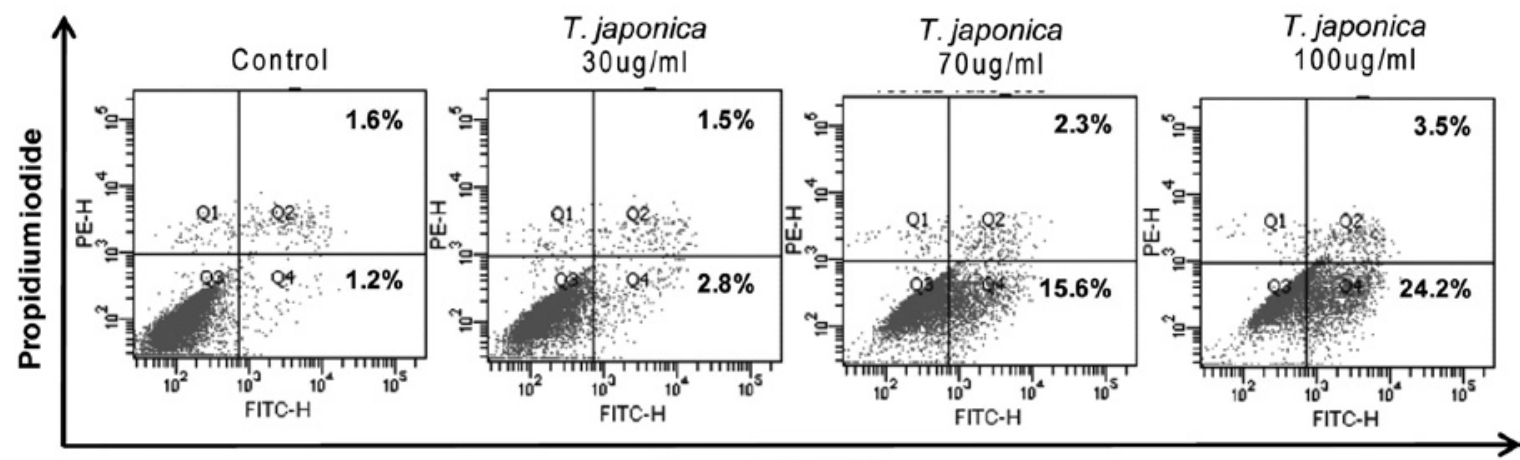

Annexin V-FITC

C

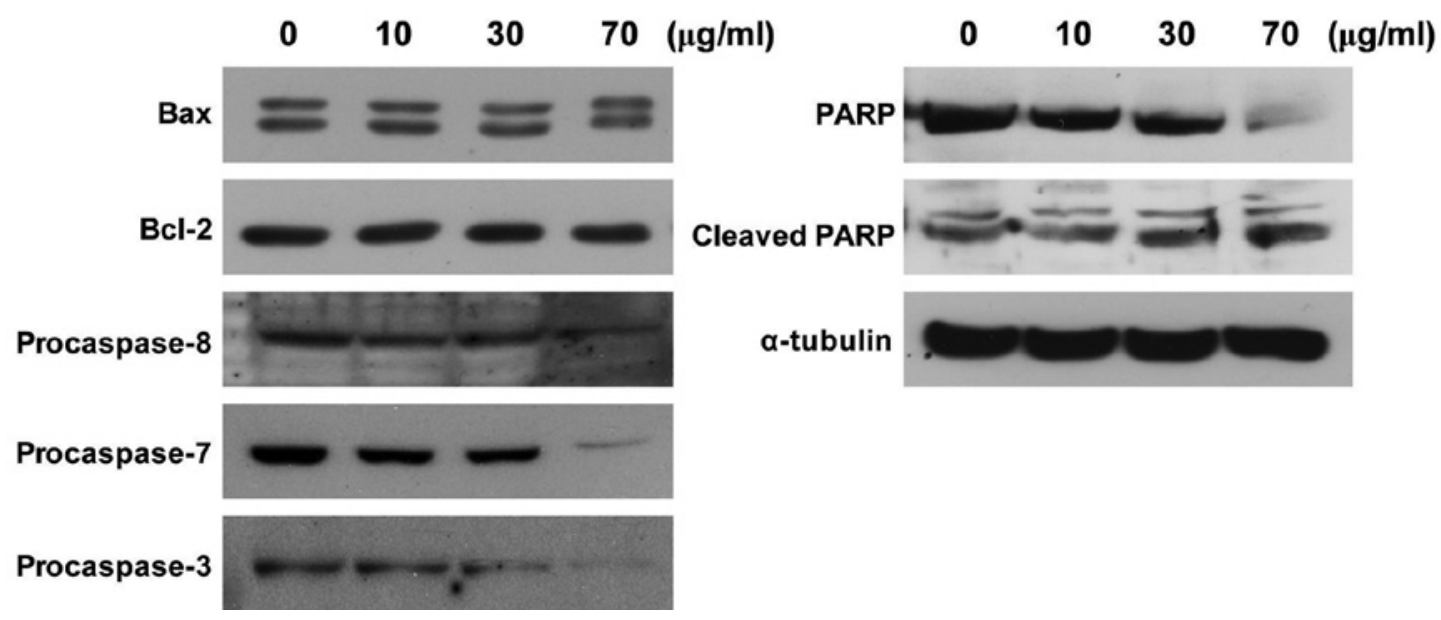

Figure 3. Apoptosis induced in U87MG cells by a T. japonica extract. (A) Cells were incubated either with or without $10 \mu \mathrm{g} / \mathrm{ml}$ of extract for $48 \mathrm{~h}$ and stained with Hoechst 33258. Arrows indicate cell nuclei with condensed chromatin. Scale bar, $50 \mu \mathrm{m}$. (B) U87MG cells were treated with the indicated concentrations of T.japonica extract for $60 \mathrm{~h}$, stained with Annexin-V/PI and analyzed by flow cytometry. (C) Cells were incubated with the indicated concentrations of $T$. japonica extract for $48 \mathrm{~h}$ and subjected to Western blotting using antibodies against apoptotic cell death-related proteins. $\alpha$-tubulin was used as an internal control.

Caspases are broadly divided into two groups: initiator caspases (caspase-2, -8, -9 and -10) and effector caspases (caspase-3, -6 and -7). Initiator caspases induce apoptosis using a death receptor-mediated signal transduction pathway. The activation of initiator caspases results in downstream signaling, leading to the activation of effector caspases (23). Caspases cleave various endogenous cellular substrates and induce the morphological and biochemical features of apoptosis, including cell shrinkage, DNA fragmentation, chromatin condensation and membrane blebbing $(22,24)$. In the present study, treatment with $T$. japonica extract increased initiator and effector caspase activation in U87MG cells, suggesting that apoptosis was induced via the death receptor mechanism.

In conclusion, we present possible pathways by which the T. japonica extract induced anti-proliferative activity in the human glioblastoma U87MG cell line. The extract prohibits S-phase cell cycle progression via down-regulation of proteins that control the cell cycle. T. japonica extract also caused mitochondria-independent and caspase-dependent apoptosis. When the present results are supplemented with in vivo experimental data on the anti-tumor effect of the T. japonica extract, it may be possible to use the extract as a promising therapeutic agent directed against human glioblastomas.

\section{Acknowledgements}

This study was supported by the Basic Science Research Program through the National Research Foundation of Korea (NRF), funded by the Ministry of Education, Science and Technology (2009-0072938). 


\section{References}

1. Singh SK, Hawkins C, Clarke ID, Squire JA, Bayani J, Hide T, Henkelman RM, Cusimano MD and Dirks PB: Identification of human brain tumour initiating cells. Nature 432: 396-401, 2004

2. Davis FG, Freels S, Grutsch J, Barlas S and Brem S: Survival rates in patients with primary malignant brain tumors stratified by patient age and tumor histological type: an analysis based on Surveillance, Epidemiology and End Results (SEER) data, 1973-1991. J Neurosurg 88: 1-10, 1998.

3. Legler JM, Gloeckler Ries LA, Smith MA, Warren JL, Eineman EF, Kaplan RS and Linet MS: Brain and other central nervous system cancers: recent trends in incidence and mortality. National Cancer Institute 91: 1382-1693, 1999.

4. Wu J, Wu Y and Yang BB: Anticancer activity of Hemsleya amabilis extract. Life Sciences 71: 2161-2170, 2002.

5. Zhou HY, Shen JK, Hou JS, Qiu YM and Luo QZ: Experimental study on apoptosis induced by elemene in glioma cells. Ai Zheng 22: 959-963, 2003.

6. Lee WH, Jin JS, Tsai WC, Chen YT, Chang WL, Yao CW, Sheu LF and Chen A: Biological inhibitory effects of the Chinese herb danggui on brain astrocytoma. Pathobiology 73: 141-148, 2006.

7. Lin J, Chen LY, Lin ZX and Zhao ML: The effect of triptolide on apoptosis of glioblastoma multiforme (GBM) cells. J Int Med Res 35: 637-643, 2007.

8. Lin J, Chen L, Lin Z and Zhao M: Inhibitory effect of triptolide on glioblastoma multiforme in vitro. J Int Med Res 35: 490-496, 2007.

9. Lee MC and Ryu KS: Studies on the constituents in the fruits. Buli KH Pharma Sci 6: 61-67, 1978.

10. Lee EB, Cho SI, Kang SS, Kim KR and Kim TH: Isolation of Torilin from Torilis japonica fruit and its analgesic and antiinflammatory activities. Kor J Pharmacogn 30: 137-144, 1999.

11. Kim MS, Lee YM, Moon EJ, Kim SE, Lee JJ and Kim KW: Anti-angiogenic activity of torilin, a sesquiterpene compound isolated from Torilis japonica. Int J Cancer 87: 269-275, 2000.

12. Oh H, Kim JS, Song EK, Cho H, Kim DH, Park SE, Lee HS and Kim YC: Sesquiterpenes with hepatoprotective activity from Cnidium monnieri on tacrine-induced cytotoxicity in Hep G2 cells. Planta Med 68: 748-749, 2002.
13. Park WS, Son ED, Nam GW, Kim SH, Noh MS, Lee BG, Jang IS, Kim SE, Lee JJ and Lee CH: Torilin from Torilis japonica, as a new inhibitor of testosterone 5 alpha-reductase. Planta Med 69: 459-461, 2003.

14. Kim DY, Kang SH and Ghil SH: Cirsium japonicum extract induces apoptosis and anti-proliferation in the human breast cancer cell line MCF-7. Mol Med Rep 3: 427-432, 2010.

15. Budihardjo I, Oliver $H$, Lutter $M$, Luo $X$ and Wang $X$ : Biochemical pathways of caspase activation during apoptosis. Annu Rev Cell Dev Biol 15: 269-290, 1999.

16. Chibazakura T: Cyclin proteolysis and CDK inhibitors: two redundant pathways to maintain genome stability in mammalian cells. Cell Cycle 10: 1243-1245, 2004.

17. Lim DY, Jeong YH, Tyner AL and Park JHY: Induction of cell cycle arrest and apoptosis in HT-29 human colon cancer cells by the dietary compound luteolin. Am J Physiol Gastrointest Liver Physiol 292: G66-G75, 2007.

18. Diehl JA: Cycling to cancer with cyclin D1. Cancer Biol Ther 1: 226-231, 2002.

19. Kitagawa M, Higashi H, Jung HK, Suzuki-Takahashi I, Ikeda M, Tamai K, Kato J, Segawa K, Yoshida E, Nishimura S and Taya Y: The consensus motif for phosphorylation by cyclin D1-Cdk4 is different from that for phosphorylation by cyclin A/E-Cdk2. EMBO J 15: 7060-8069, 1996.

20. Hasenjäger A, Gillissen B, Müller A, Normand G, Hemmati PG, Schuler M, Dörken B and Daniel PT: Smac induces cytochrome c release and apoptosis independently from $\mathrm{Bax} / \mathrm{Bcl}-\mathrm{x}(\mathrm{L})$ in a strictly caspase-3-dependent manner in human carcinoma cells. Oncogene 23: 4523-4535, 2004.

21. Kim R, Emi M and Tanabe K: Caspase-dependent and -independent cell death pathways after DNA damage. Oncol Rep 14: 595-599, 2005.

22. Orrenius S: Mitochondrial regulation of apoptotic cell death. Toxicol Lett 149: 19-23, 2004.

23. Stennicke HR and Salvesen GS: Properties of the caspases. Biochim Biophys Acta 1387: 17-31, 1998.

24. Moore JD, Rothwell NJ and Gibson RM: Involvement of caspases and calpains in cerebrocortical neuronal cell death is stimulus-dependent. Br J Pharmacol 135: 1069-1077, 2002. 